\title{
Combined vitrectomy and intravitreal injection versus combined laser and injection for treatment of intractable diffuse diabetic macular edema
}

This article was published in the following Dove Press journal:

Clinical Ophthalmology

12 February 2013

Number of times this article has been viewed

\author{
Ahmed M Saeed \\ Department of Ophthalmology, Benha \\ University, Benha, Egypt
}

Background: The purpose of this study was to compare the safety and efficacy of combined vitrectomy, intravitreal triamcinolone acetonide (IVTA), and bevacizumab injection with that of IVTA and bevacizumab injection and subsequent macular grid laser photocoagulation for the treatment of intractable diffuse diabetic macular edema.

Methods: This randomized controlled clinical trial was performed at Benha University Hospital, Benha, Egypt, and included 34 eyes from 34 diabetic patients diagnosed with intractable diffuse diabetic macular edema without vitreomacular traction. The patients were divided into two groups. In group 1, pars plana vitrectomy with removal of the posterior hyaloid was performed, and at the end of the procedure, IVTA $0.1 \mathrm{~mL}(40 \mathrm{mg} / \mathrm{mL})$ and bevacizumab $1.25 \mathrm{mg}$ were injected. In group 2, macular grid laser photocoagulation was performed 2 weeks after the same intravitreal injection combination as used in group 1. The main outcome measures were best-corrected visual acuity (BCVA) and central foveal thickness, which were measured using optical coherence tomography at 3,6, and 12 months.

Results: Changes in BCVA and central foveal thickness at 3, 6, and 12 months from baseline were highly statistically significant $(P<0.01)$. Mean BCVA was better in group 1 at 3 months, nearly equal at 6 months, and less at 12 months. Mean central foveal thickness was more improved in group 1 than in group 2 at 3 months, and was better in group 2 at subsequent measurement points. The major adverse events were development of cataract (more common in group 1) and elevation of intraocular pressure (more common in group 2).

Conclusion: The combined therapy described here could represent a solution for the treatment of intractable diabetic macular edema, and could have a favorable long-term outcome. Combined treatment of IVTA and bevacizumab plus grid laser resulted in a more favorable reduction in central foveal thickness and improvement in BCVA at 12 months than vitrectomy combined with the same injections. This small study favors the safer, cheaper, and more available line of treatment.

Keywords: intractable diffuse diabetic macular edema, intravitreal triamcinolone, bevacizumab injection, macular grid laser photocoagulation, central foveal thickness

\section{Introduction}

An estimated 346 million people were affected by diabetes worldwide in 2011, and the number of people with the disease is expected to double from 2005 to 2030. ${ }^{1}$ Diabetic retinopathy is the leading cause of loss of vision in adults of working age, ${ }^{2}$ and diabetic macular edema is the most frequent cause of vision loss related to diabetes, especially in patients with a long duration of disease.

Argon laser photocoagulation has been the mainstay of treatment for macular edema since publication of the results of the Early Treatment Diabetic Retinopathy
Saeed

Zayed Tower, El-Souq Eltougary St,

El-Qanatir El-Khairiya, Al-Qalyubiyah

I362 I, Egypt

Tel +20 I2 27468426

Email a_saeed775@yahoo.com 
Study (EDRTS). Over the last few years, intravitreal corticosteroids and intravitreal antivascular endothelial growth factor agents have also entered common clinical use, either alone or in combination with focal/grid laser for the management of diabetic macular edema, and several recent randomized clinical trials have shown improved effectiveness compared with focal/grid laser. ${ }^{3-5}$

However, there have been patients with diffuse diabetic macular edema refractory to such treatment modalities. In cases of intractable diffuse diabetic macular edema that persists or recurs after laser photocoagulation or intravitreal triamcinolone injection (IVTA), limited treatment benefits are expected. This is because of the structural damage caused by chronic macula edema and the underlying diabetic retinopathy.

The vitreous and vitreoretinal junction have been identified as being modulators of diabetic macular edema, ${ }^{6-12}$ although their precise role in the pathogenesis of diabetic maculopathy is widely debated. ${ }^{13}$ Encouraged by reports showing that diabetic patients with posterior vitreous detachment are less likely to develop diabetic macular edema $^{11}$ and that resorption may occur after spontaneous posterior vitreous detachment, ${ }^{7,14}$ vitrectomy with removal of the posterior hyaloid has been considered to be a therapeutic option in diffuse and cystoid edema, which often persists despite multiple laser treatments. ${ }^{10,12,15}$ Successful vitrectomy has been reported not only in selected patients with diabetic macular edema associated with visible posterior hyaloid traction, ${ }^{10}$ but also reported in eyes when macular traction was stated to be absent. ${ }^{9,16,17}$

The aim of this trial was to compare the safety and the efficacy of combined vitrectomy, IVTA, and bevacizumab injection with that of combined IVTA and bevacizumab injection and subsequent macular grid laser photocoagulation for the treatment of intractable diffuse diabetic macular edema.

\section{Materials and methods}

This randomized, controlled, prospective clinical trial was carried out in the ophthalmology department at Benha University Hospital during the period from November 2010 to July 2012. Evaluation was done preoperatively and up to 12 months postoperatively. The study included 34 eyes from 34 patients with type 2 diabetes mellitus (17 males and 17 females). Four patients (two in each group) were excluded from the study because they missed two postoperative visits. Informed consent was obtained from all patients enrolled in the study after the nature and possible consequences of the procedures had been explained. Only one eye per participant could be enrolled. All patients had been diagnosed with intractable diffuse diabetic macular edema, which was defined as biomicroscopically, angiographically, and tomographically confirmed diffuse diabetic macular edema which did not respond to or recurred after IVTA and/or macular focal laser photocoagulation. Central foveal thickness had to be greater than $300 \mu \mathrm{m}$.

Exclusion criteria included the presence of vitreomacular traction, active neovascularization of proliferative diabetic retinopathy, an enlarged foveal avascular zone on fluorescein angiography, neurosensory detachment on optical coherence tomography, treatment for diabetic macular edema within the previous 3 months, previous vitreoretinal surgery, other major ocular surgery (including cataract extraction, scleral buckle, or other intraocular surgery) within the previous 6 months, YAG capsulotomy performed within the 2 months prior to enrollment, other macular pathology (eg, age-related macular degeneration, retinal vascular occlusive diseases, combined optic neuropathy, glaucoma including neovascular glaucoma, vitreous hemorrhage), refusal to provide written informed consent, or missing two follow-up visits.

Baseline evaluation included measurement of best corrected visual acuity (BCVA) using the ETDRS chart and reported as EDRTS acuity log score, intraocular pressure using applanation tonometry, slit-lamp biomicroscopy, dilated fundus examination, fundus fluorescein angiography using a Visucam Lite device (AG 07740, Carl Zeiss Meditec, Jena, Germany), and optical coherence tomography (Cirrus HD-OCT 4000, Carl Zeiss Meditec). Central foveal thickness was defined as the distance between the inner retinal surface and the retinal pigment epithelium at the central fovea. Systemic hypertension, mean glycosylated hemoglobin $\left(\mathrm{HbA}_{1 \mathrm{c}}\right)$ levels, hemoglobin, lipid profile, and prothrombin time and concentration were controlled at baseline.

The 30 patients ( 15 males and 15 females) were randomly divided into two groups. In group $1(\mathrm{n}=15)$, pars plana vitrectomy with removal of the posterior hyaloid was performed, and at the end of the procedure, IVTA $0.1 \mathrm{~mL}$ $(40 \mathrm{mg} / \mathrm{mL})$ and bevacizumab $1.25 \mathrm{mg}$ were injected. In group $2(n=15)$, macular grid laser photocoagulation was performed 2 weeks after the same combination of intravitreal injection as used in group 1 . There were no statistically significant differences between the study groups with regard to age, gender, stage of diabetic retinopathy, previous treatment of diabetic macular edema, lens status, intraocular pressure values, or medical conditions $(P>0.05$, see Table 1$)$. Systemic hypertension, controlled with oral hypotensive 
Table I Baseline demographic and clinical data for both treatment groups

\begin{tabular}{llll}
\hline Variable & Group I & Group 2 & P values \\
\hline Age, years (mean \pm SD) & $54 \pm 8.6$ & $57 \pm 7.5$ & $>0.05$ \\
Gender (males to females) & $8: 7(53.3 \%: 46.7 \%)$ & $7: 8(46.7 \%: 53.3 \%)$ & 0.72 \\
Duration of diabetes, years (mean \pm SD) & $23 \pm 6.2$ & $25 \pm 4.6$ & $>0.05$ \\
Stage of DR, number of cases & $1: 9: 5$ & $1: 10: 4$ & 0.92 \\
(moderate to severe NPDR to PDR) & $(6.7 \%: 60 \%: 33.3 \%)$ & $(6.7 \%: 66.7 \%: 26.7 \%)$ & 0.89 \\
Previous treatment, number of cases & $7: 5: 3$ & $6: 5: 4$ & $(40 \%: 33.3 \%: 26.7 \%)$ \\
(macular laser to IVTA to both) & $(46.7 \%: 33.3 \%: 20 \%)$ & $10: 5$ & 0.70 \\
Lens status, number of cases & $9: 6$ & $(66.7 \%: 33.3 \%)$ & \\
(phakic to pseudophakic) & $(60 \%: 40 \%)$ & & \\
Intraocular pressure & & & \\
\hline
\end{tabular}

Abbreviations: DR, diabetic retinopathy; IVTA, intravitreal triamcinolone acetate; PDR, proliferative diabetic retinopathy; NPDR, nonproliferative diabetic retinopathy; $\mathrm{SD}$, standard deviation.

medications, was reported for $21 / 30$ patients (10 and 11 patients in groups 1 and 2, respectively). Mean $\mathrm{HbA}_{1 \mathrm{c}}$ levels were 7.95 and 8.13 in groups 1 and 2, respectively, and 25/30 were on insulin therapy (12 and 13 patients in groups 1 and 2, respectively).

\section{Intervention}

\section{Group I}

All patients were given preoperative topical atropine sulfate $1 \%$ and antibiotic-steroid drops (Dexaflox ${ }^{\circledR}$, Jamjoom Pharma, Jeddah, Saudi Arabia) three times daily. Surgeries were performed under local peribulbar anesthesia by the same surgeon (AMS). A standard 20 gauge pars plana vitrectomy was performed, ie, three sclerotomies, removal of the vitreous gel with the vitrectomy probe of a machine from DORC (a collaboration between Zuidland, The Netherlands, and Synergetics Inc, St Charles, MO, USA) at a cutting rate of 1200 cuts per minute, and a vacuum of $150 \mathrm{mmHg}$ in the region of the central portion of the vitreous gel. Diluted triamcinolone acetonide powder was injected into the mid vitreous cavity to stain the cortical vitreous and assist in its complete removal, which involved peeling the posterior hyaloid by applying gentle vacuum with the probe or suction by the flute needle close to the optic nerve head till engagement, then pulling upwards. The internal limiting membrane was intentionally left. The vitreous base was removed as far as possible with a lower vacuum of $100 \mathrm{mmHg}$ and a higher cutting rate of 1600 cuts per minute. The lens was spared in all phakic patients, with peeling of any peripheral epiretinal membranes which could potentially be a threat to vision. The peripheral retina was examined, and any detected tear was surrounded by two rows of endolaser photocoagulation spots. Next, closure of the sclerotomies and conjunctiva was performed using 7/0 Vicryl ${ }^{\circledR}$ sutures (polyglactin 910; Ethicon Inc, Johnson and Johnson, Somerville, NJ, USA).
At the end of the procedure, IVTA $0.1 \mathrm{~mL}(40 \mathrm{mg} / \mathrm{mL}$ of Kenacort-A ${ }^{\circledR}$, GlaxoSmithKline, Philadelphia, PA, USA) and bevacizumab (1.25 mg, Avastin ${ }^{\circledR}$, Roche, Basel, Switzerland) were injected. Postoperatively, prednisolone acetate $1 \%$ and gatifloxacin $0.3 \%$ (Optipred $^{\circledR}$ and Tymer $^{\circledR}$, respectively, Jamjoom Pharma, Jeddah, Saudi Arabia) eye drops were administered five times daily for 3 weeks.

\section{Group 2}

The same injections of IVTA $0.1 \mathrm{~mL}(40 \mathrm{mg} / \mathrm{mL})$ and bevacizumab $1.25 \mathrm{mg}$ were given at two separate injection sites under completely sterile conditions in the operating room under microscopic visualization at distances of $4 \mathrm{~mm}$ and $3.5 \mathrm{~mm}$ from the limbus in phakic and pseudophakic patients, respectively. Paracentesis was done first to soften the eye. Next, gatifloxacin $0.3 \%$ eye drops were prescribed four times daily for one week. Argon laser photocoagulation was applied 2 weeks following the injections using an Ellex Integre device (Ellex Medical Pty Ltd, Adelaide, Australia). Grid laser $(532 \mathrm{~nm})$ to areas of thickened retina showing diffuse fluorescein leakage or capillary dropout. Burns (100-200) of light intensity were placed 100-200 $\mu \mathrm{m}$ apart in this area using $100 \mu \mathrm{m}$ spots $0.1-0.05$ seconds in duration. Grid treatment was not applied within $500 \mu \mathrm{m}$ of the center of the macula or within $500 \mu \mathrm{m}$ of the disk margin. If present, any focal leaks within the zone of grid treatment were treated focally by a $100-150 \mu \mathrm{m}$ spot applied for 0.1 second in duration to treat all lesions that leaked fluorescein.

\section{Study visits}

Group 1 made study visits at one week, and one, 3, 6, and 12 months postoperatively, and group 2 study visits were in the same sequence following application of grid laser. Additional visits were scheduled according to the patient's condition and any reported complications. At each visit, 
all eyes underwent ETDRS visual acuity testing, anterior segment biomicroscopy (keratopathy, anterior chamber reaction, and lens cataract changes), intraocular pressure, fundus examination (retinal attachment, vitreous hemorrhage, or proliferation), fundus fluorescein angiography, and optical coherence tomography. Cases with intraocular pressure $>22 \mathrm{mmHg}$ were given antiglaucoma medication, with rapid tapering of topical steroids if possible. Blood pressure and HbA1c levels were measured at 3, 6, and 12 months following the study intervention. As the main outcome measures, BCVA was recorded and central foveal thickness was measured using optical coherence tomography at 3, 6, and 12 months (Figures 1-8).

\section{Statistical analysis}

The collected data were tabulated and analyzed using SPSS version 16 software (IBM Corporation, Armonk, NY, USA).
Categorical data are presented as numbers and percentages, while quantitative data are expressed as the mean and standard deviation. The paired $t$-test was used as a test of significance for comparing preoperative and postoperative data in the study group. $P<0.05$ was considered to be statistically significant, and $P<0.001$ was considered to be highly significant.

\section{Results}

\section{Main outcome measures}

In both study groups, there was a high statistically significant $(P<0.001)$ increase in BCVA during the postoperative study visits when compared with baseline values, as shown in Figure 9. Table 2 compares the mean BCVA and central foveal thickness measurements in the two groups during the study period.

Mean improvement in BCVA was higher in group 1 at 3 months, nearly equal but still higher at 6 months, and less at

Macula thickness: macular cube $512 \times 128$

OD O O OS
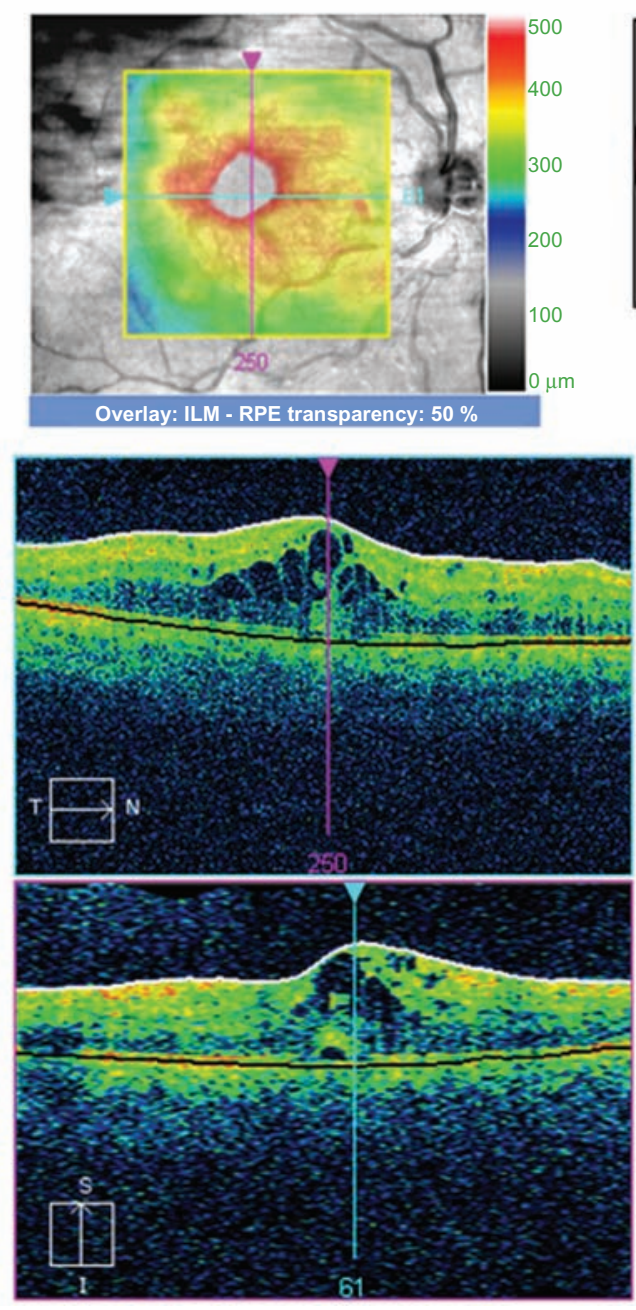

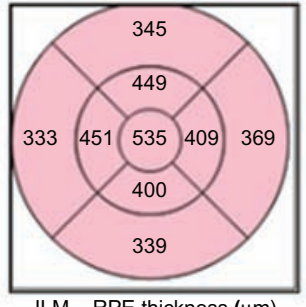

ILM - RPE thickness $(\mu \mathrm{m})$
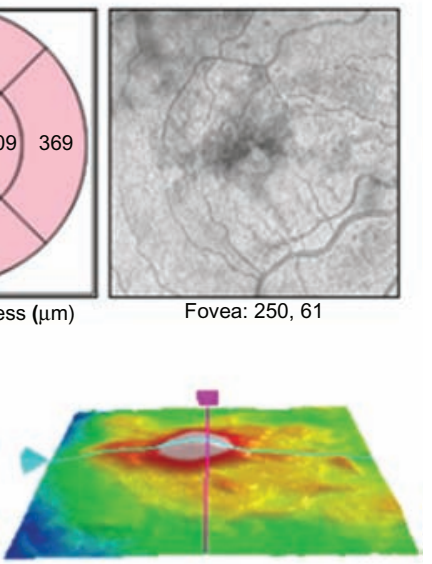

ILM-RPE

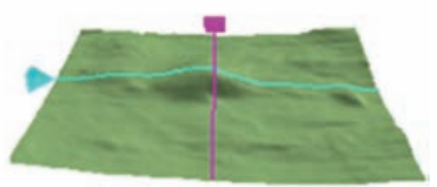

ILM

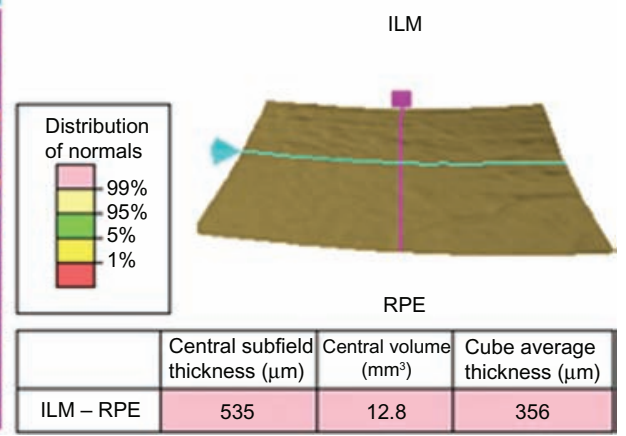

Figure I Optical coherence tomograph of a patient in group I at the preoperative visit. Abbreviations: ILM, inner limiting membrane; RPE, retinal pigment epithelium. 


\section{Macula thickness: macular cube $512 \times 128 \quad$ OD $\bigcirc \mid \bigcirc$ OS}

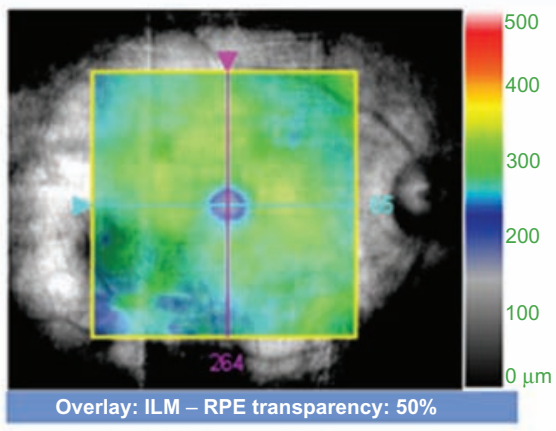

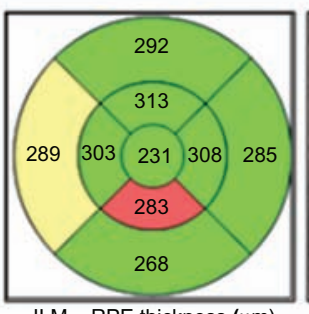

ILM - RPE thickness $(\mu \mathrm{m})$

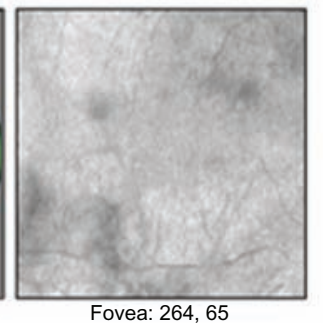

Fovea: 264,65

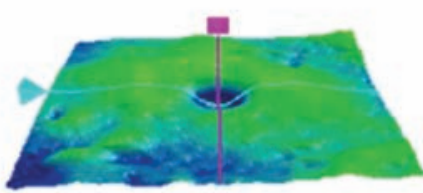

ILM - RPE

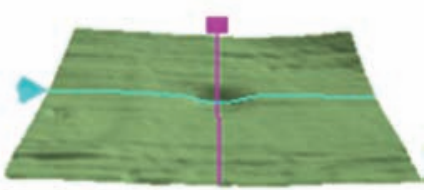

ILM

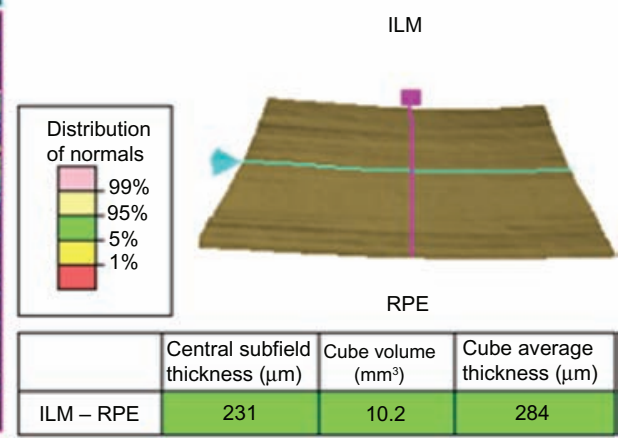

Figure 2 Optical coherence tomograph of the same patient in group I at the 3-month preoperative visit. Abbreviations: ILM, inner limiting membrane; RPE, retinal pigment epithelium.

12 months. However, these differences were not statistically significant $(P>0.05)$ during the follow-up study visits, as shown in Table 3 and Figure 11. BCVA at 12 months had improved by more than two lines compared with baseline in 10 eyes (66.6\%) in each group, and had decreased by two lines in one eye in group 1 only.

In both study groups, there was a statistically significant decrease in central foveal thickness during the postoperative study visits when compared with baseline $(P<0.001)$, as shown in Figure 10. The mean central foveal thickness reduction was higher in group 1 than in group 2 at 3 months, and was better in group 2 later on. However, these differences were not statistically significant over all the follow-up study visits $(P>0.05)$, as shown in Table 3 and Figure 12. It was also observed that the mean central foveal thickness in both groups showed maximum improvement at 3 months, with a subsequent small gradual increase in central foveal thickness at 6 and 12 months, which was still markedly less than at baseline.

There was no recorded difference in mean central foveal thickness between eyes that had received macular argon laser before the study (10 eyes, 66\% in each group) and eyes that had received IVTA injection alone (five eyes, 33.3\%) in either group when comparing the results at 12 months with baseline values $(P>0.05)$. Group 2 achieved better results for mean BCVA and central foveal thickness values than group 1 at the end of the study period; however, the difference did not reach statistical significance, as shown in Table 3 and Figures 11 and 12. Table 3 shows the improvement in BCVA and change in central foveal thickness from baseline values in both groups during the study period. Figure 9 shows mean BCVA measured by EDRTS acuity log score, Figure 10 shows the mean central foveal thickness, Figure 11 shows mean BCVA improvement, and Figure 12 shows mean change in central 


\section{Macula thickness: macular cube $512 \times 128 \quad$ OD $\bigcirc \mid \bigcirc$ OS}
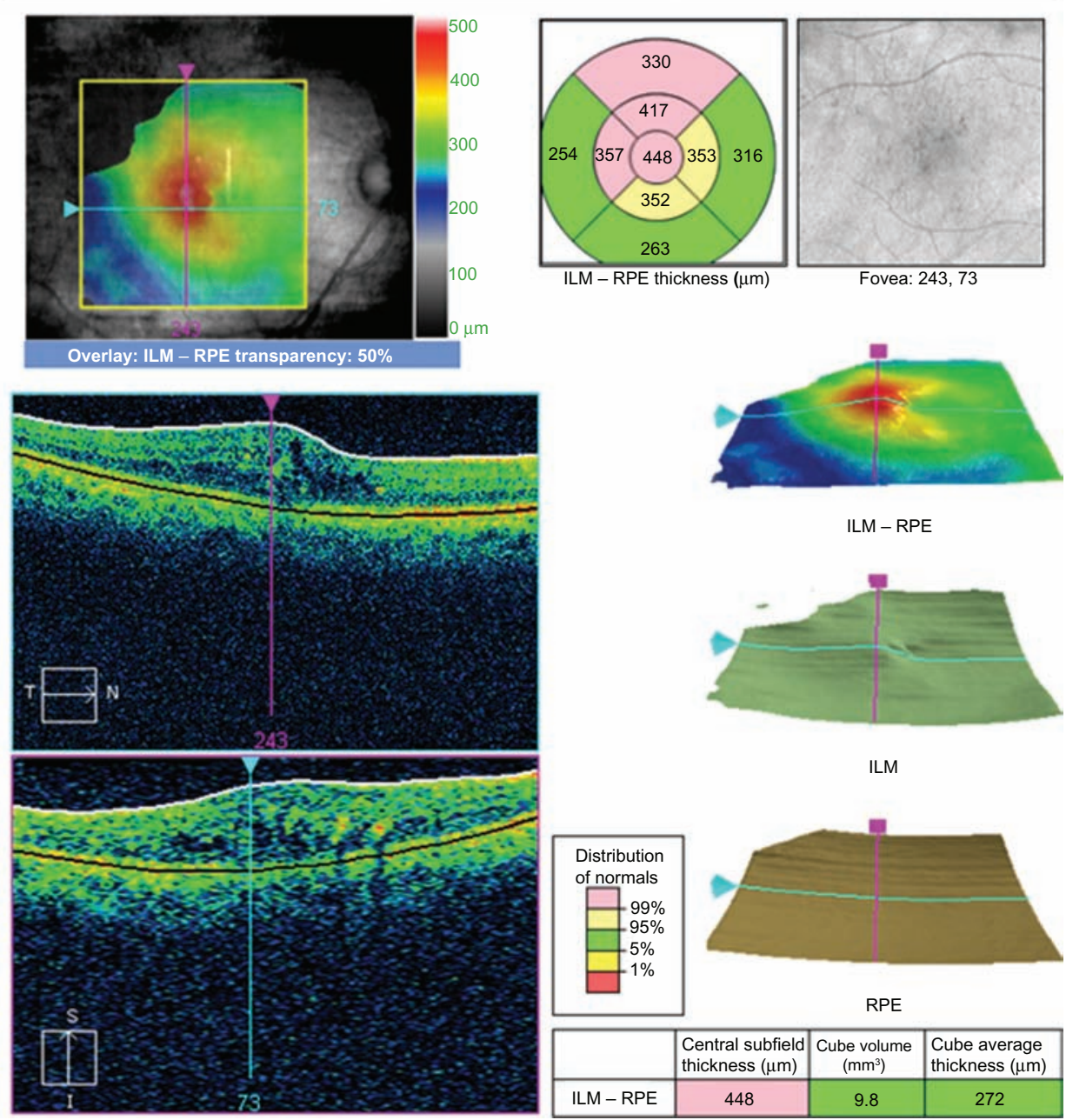

Figure 3 Optical coherence tomograph for a patient in group 2 at the preoperative visit. Abbreviations: ILM, inner limiting membrane; RPE, retinal pigment epithelium.

foveal thickness from the baseline values in both groups during the study period.

During pars plana vitrectomy in group 1, posterior vitreous detachment was already evident in 11 eyes (eight eyes already received previous IVTA injection) and was created in four eyes. Vitreoschisis was observed in three eyes, and was detected by mid IVTA injection and posterior hyaloid separation on two occasions.

The major adverse events were elevation of intraocular pressure (more in group 2) and development of cataract (more in group 1). Elevation of intraocular pressure was reported in two eyes (13.3\%) and seven eyes (46.6\%) in groups 1 and 2, respectively. Elevated intraocular pressure was recorded after IVTA injection within a variable time period (range 4 days to 3 weeks). Intraocular pressure was controlled medically in all cases (nine eyes) with topical antiglaucoma drops, ie, timolol maleate $0.5 \%$
(Egyptian International Pharmaceutical Industries Company, Cairo, Egypt), dorzolamide $\mathrm{HCl}$ 2\% (Trusopt, Merck and Co, Inc, Whitehouse Station, NJ, USA), and brimonidine tartrate $0.2 \%$ (Alphagan ${ }^{\circledR}$, Allergan Inc, Irvine, CA, USA). Two cases were controlled by one drug, four cases by two drugs, and three cases by three drugs. The duration of administration of antiglaucoma medication was variable (range 3-11 weeks), with subsequent gradual withdrawal and maintenance of intraocular pressure monitoring.

There were no statistically significant differences in mean intraocular pressure values when comparing the two groups at baseline. Although group 2 showed higher mean intraocular pressure values than group 1 at one, 3 , and 6 months following intervention (especially at one month), the differences were not statistically significant, as shown in Table 4 . When comparing mean baseline values with mean post-intervention values, only group 2 showed a statistically 


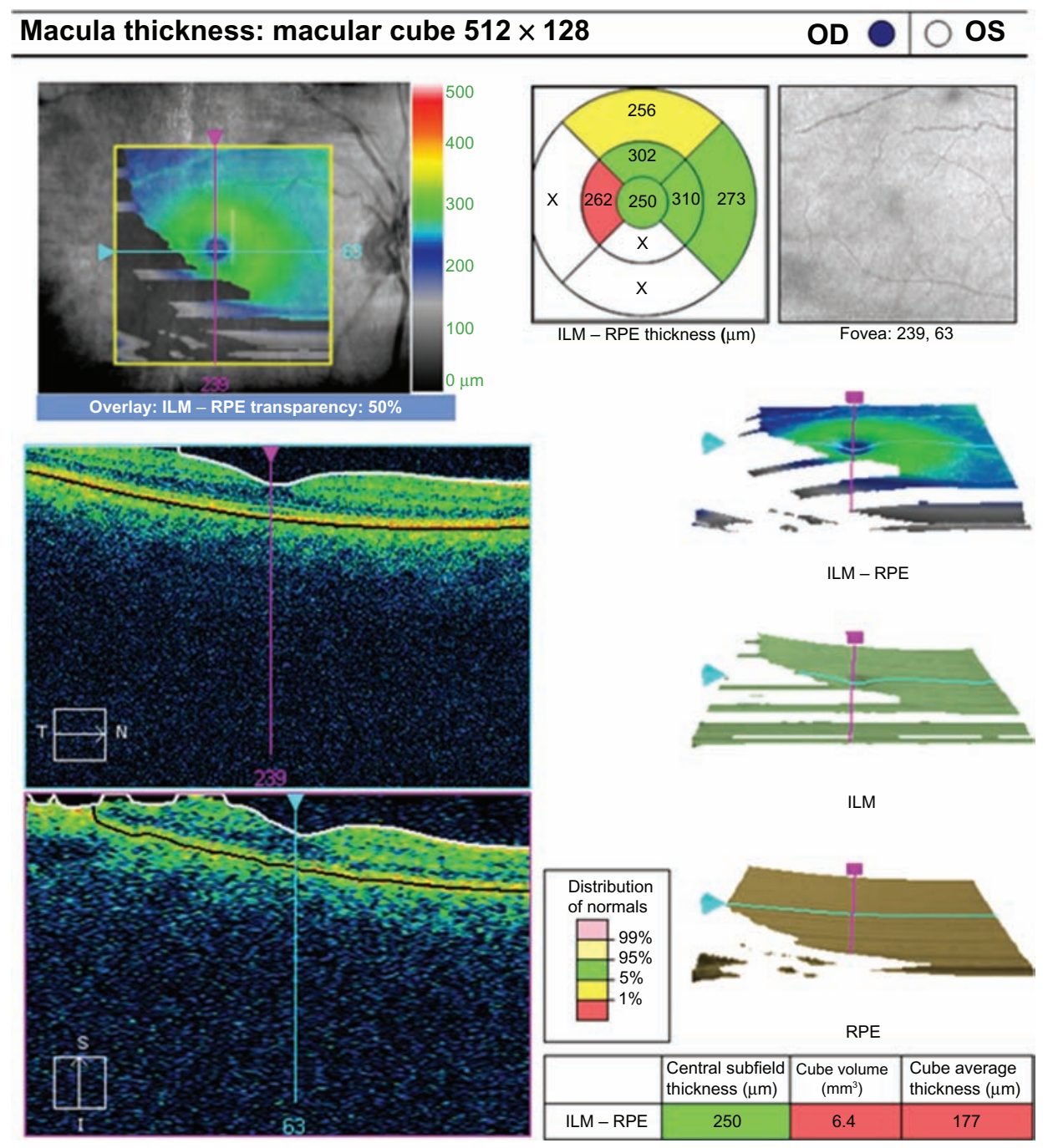

Figure 4 Optical coherence tomograph for the same patient in group 2 at the 3-month postperative visit. Abbreviations: ILM, inner limiting membrane; RPE, retinal pigment epithelium.

significant increase in intraocular pressure at one month $(P=0.002)$.

Development of cataract was reported in six eyes (66.6\%) and three eyes (30\%) in groups 1 and 2, respectively. Cataract had become visually significant at the 6-month visit, and all patients with cataract (nine eyes) had undergone uneventful phacoemulsification with injectable foldable in-the-bag posterior chamber intraocular lens implantation and application of perioperative topical nonsteroidal antiinflammatory ketorolac tromethamine $0.5 \%$ drops (Acular, Allergan Inc).

No other major complications (such as endophthalmitis, retinal detachment, significant vitreous or retinal hemorrhage, choroidal hemorrhage, or atrophia bulbi) were noted. $\mathrm{HbA}_{1 \mathrm{c}}$ levels were measured at 3, 6, and 12 months following intervention. Mean $\mathrm{HbA}_{1 \mathrm{c}}$ levels were 7.81, 8.21, and 8.34 in group 1 at 3, 6, and 12 months postoperatively, and 7.97,
8.11, and 8.29 in group 2 at 3, 6, and 12 months following intervention.

\section{Discussion}

The natural history of diabetic macular edema is progressive visual loss, with more than $50 \%$ of patients losing more than two lines of visual acuity within 2 years. ${ }^{18}$ The ETDRS showed that laser photocoagulation stabilized vision and reduced the risk of visual loss by $50 \% .{ }^{19}$ Laser photocoagulation and IVTA results were not satisfactory in many cases because of recurrent or persistent diabetic macular edema. The vitreous has been implicated as a cause of diabetic macular edema via several mechanical and physiologic mechanisms, all of which lead to increased vascular permeability. Suggested mechanisms include destabilization of the vitreous by abnormal glycation and crosslinking of vitreal collagen leading to traction on the macula, accumulation and 


\section{Macula thickness: macular cube $512 \times 128 \quad$ OD $\bigcirc \mid \bigcirc$ OS}
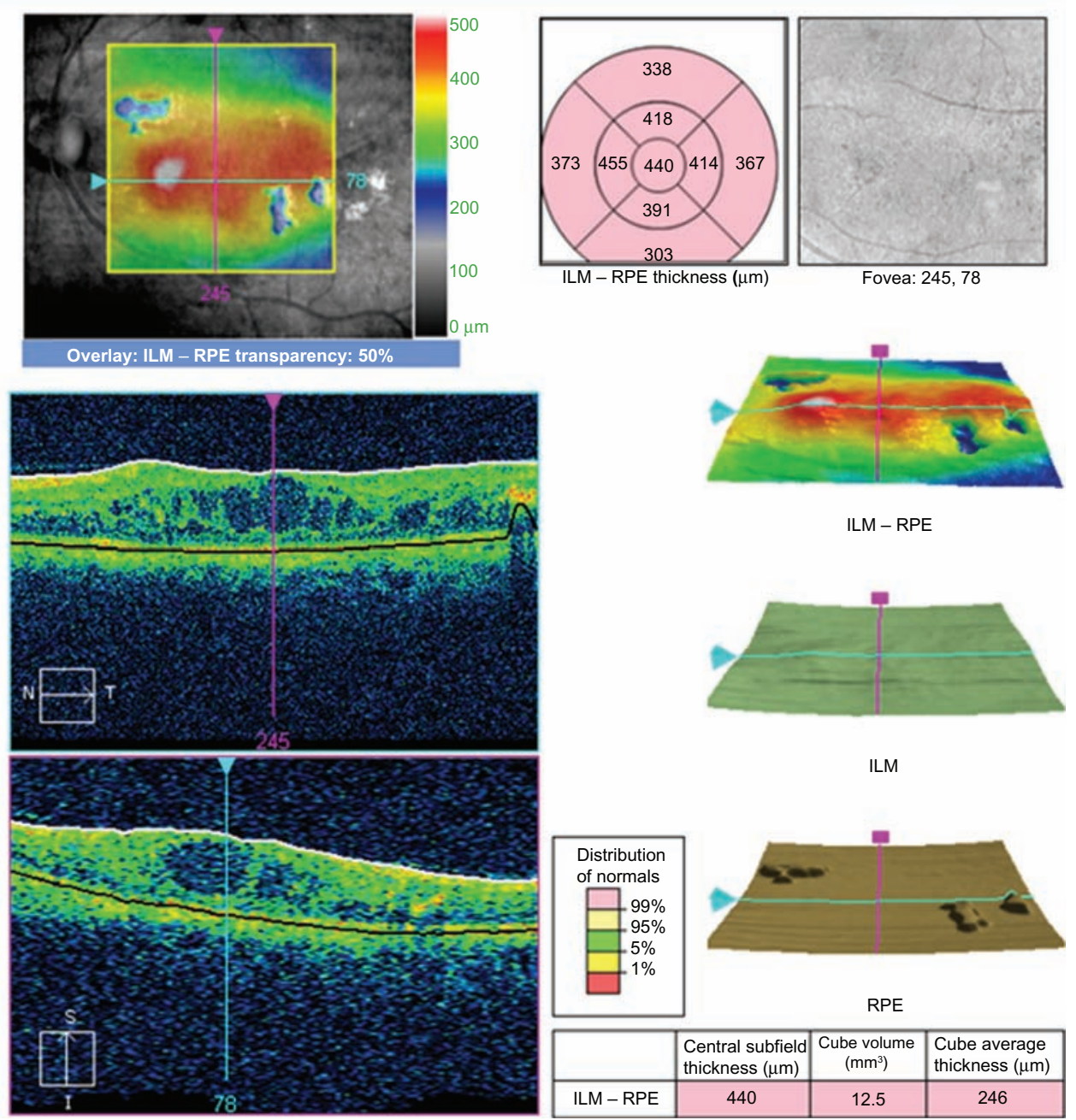

Figure 5 Optical coherence tomograph for a patient in group I at the preoperative visit. Abbreviations: ILM, inner limiting membrane; RPE, retinal pigment epithelium.

concentration of factors causing vasopermeability in the premacular vitreous gel, and accumulation of chemoattractant factors in the vitreous, leading to migration of cells to the posterior hyaloid, contraction, and macular traction. . $, 15,16,20-22^{2}$ The spectrum of indications for vitrectomy has been extended to include diabetic macular edema with or without taut posterior hyaloid. ${ }^{23}$ Various studies suggest that the presence of tangential vitreomacular tractional forces combined with local presence of a number of cytokines (eg, interleukin-6) and growth factors (vascular endothelial growth factor and angiotensin) contribute to the development of diabetic macular edema, and their removal benefits macular edema and helps to delay its progression. ${ }^{10,12,24-26}$ Ikeda et $\mathrm{al}^{8}$ suggested that removal of the barrier between the vitreous cavity and retina by pars plana vitrectomy might lead to improved diffusion of fluid from the retinal tissue. Further, Stefansson et $\mathrm{al}^{27,28}$ have suggested that fluid currents in the vitreous cavity following vitrectomy transport oxygen from well perfused areas of the retina to hypoxic areas, such as in diabetic macular edema, indicating an additional physiologic advantage of vitrectomy.

Another controversial subject is removal of the internal limiting membrane during vitrectomy. Removal of this membrane may have the additional benefit of preventing later epiretinal membrane formation by removing the scaffold for proliferating cells. However, in this trial, it was decided not to peel the internal limiting membrane for eyes with chronic diffuse diabetic macular edema, because of concerns about further photoreceptor damage in an already damaged macula by removing the membrane, possible indocyanine green dye toxicity during staining of the internal limiting membrane, and potential alteration in Müller cell physiology after its removal, which may explain the lack of significant improvement in vision despite a marked resolution of 


\section{Macula thickness: macular cube $512 \times 128$} OD $\bigcirc \mid \circ$ OS

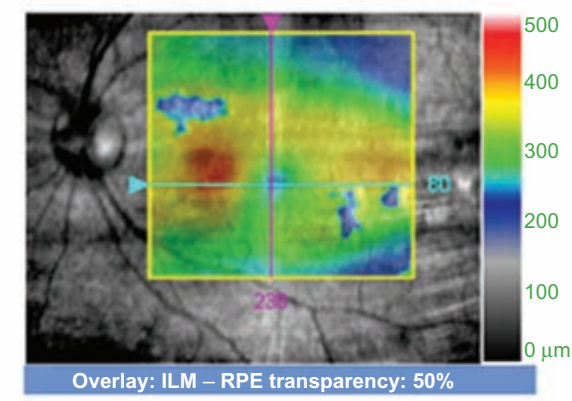

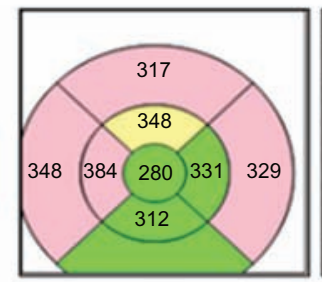

ILM - RPE thickness ( $\mu \mathrm{m})$

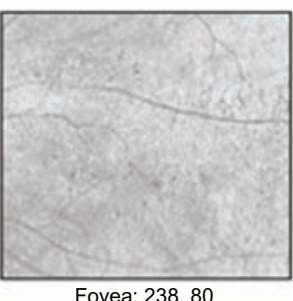

Fovea: 238,80

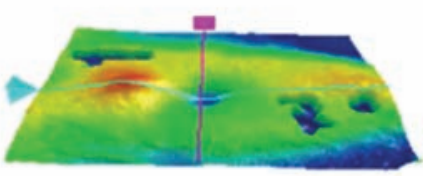

ILM - RPE

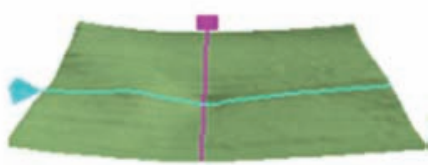

ILM

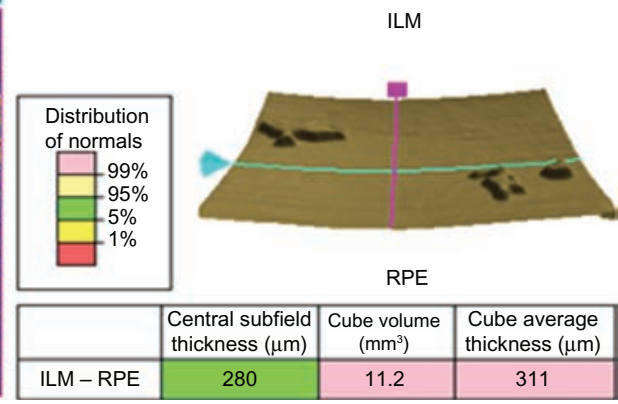

Figure 6 Optical coherence tomograph for the same patient in group I at the I2-month visit. Abbreviations: ILM, inner limiting membrane; RPE, retinal pigment epithelium.

macular edema. ${ }^{29-31}$ Some reports have shown that removal of the internal limiting membrane has better anatomic as well as functional results, ${ }^{6,32}$ while others have reported the opposite. $^{33,34}$

The results of this clinical trial show a highly statistically significant increase in BCVA at all postoperative study visits when compared with baseline values in both groups $(P<0.001)$. These visual results were better than expected from the photoreceptor damage caused by chronic macular edema, underlying diabetic retinopathy changes, and prior macular laser photocoagulation treatment which was an inclusion criterion for this study. However, this marked visual improvement might also reflect the cases of diabetic macular edema that were excluded from this trial, such as those with ischemic maculopathy, neurosensory detachment, and active proliferative diabetic retinopathy, which are the most common causes of lack of visual improvement in diabetic macular edema. However, the aforementioned factors still had their impact on the functional results, which were less beneficial when compared with the more promising anatomic findings. Moreover, the limited functional results in this study may have been attributable to the included cases of proliferative diabetic retinopathy (five and four cases in groups 1 and 2, respectively), and the influence of elevated HbAlc levels and poor blood pressure control.

When comparing BCVA at 12 months with baseline values, it was found that it improved by more than two lines in 10 eyes $(66.6 \%)$ in each group. These results are consistent with those reported by Song et al, ${ }^{34}$ who achieved a BCVA improvement of more than two lines in $49 \%$ of eyes following pars plana vitrectomy for persistent diabetic macular edema, and the good results in the current study could be due to the additive effect of IVTA and bevacizumab injection used in combination. Group 1 had one case of BCVA being decreased by two lines, which could be related to the effects of the vitrectomy procedure on the macula as mentioned before, proliferative 


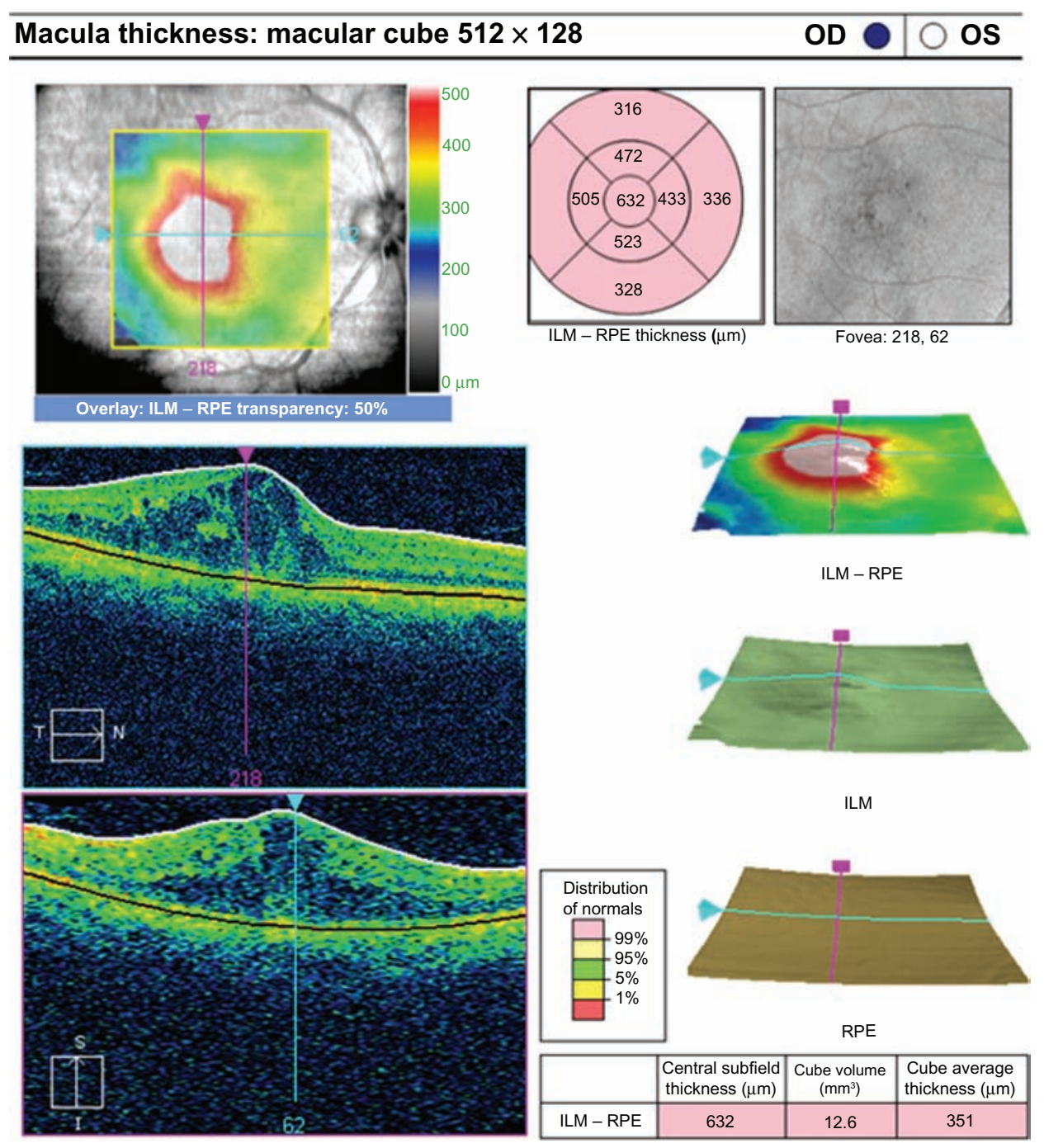

Figure 7 Optical coherence tomograph for a patient in group 2 at the preoperative visit. Abbreviations: ILM, inner limiting membrane; RPE, retinal pigment epithelium.

diabetic retinopathy changes in this patient, high blood glucose $\left(\mathrm{HbA}_{1 \mathrm{c}}>9.8 \%\right)$, and poor blood pressure control $(>150 / 105 \mathrm{mmHg})$.

In this trial, there was a highly statistically significant decrease in central foveal thickness at all postoperative study visits when compared with baseline values in both groups. This result in the vitrectomy group suggests that the presence of vitreomacular traction (which was an exclusion criterion in this trial) did not affect the surgical results of pars plana vitrectomy in intractable diffuse diabetic macular edema; this was also reported by Song et $\mathrm{ll}^{34}$ who recommended early surgical intervention for eyes with intractable diffuse diabetic macular edema. Others have reported that for eyes without taut posterior hyaloid and in eyes with posterior vitreous detachment, the efficacy of pars plana vitrectomy is controversial. ${ }^{26,35}$ However, it is worth mentioning that identification of the posterior hyaloid by biomicroscopy is notoriously difficult, and even optical coherence tomography can visualize the vitreoretinal interface only when it is partially detached or when the posterior vitreous detachment is located within a few micrometers from the retinal surface. Even during surgery, it may be hard to distinguish a posterior vitreous detachment from vitreoschisis, especially in patients with longstanding diabetic retinopathy. Also, eyes in group 2 showed a highly statistically significant decrease in central foveal thickness at all postoperative study visits when compared with baseline values, and the results were comparable with those in group 1, with no statistically significant difference found at any study visit. This suggests that macular grid laser following combined IVTA and bevacizumab injection seems to be as effective as or even better than pars plana vitrectomy with the same injections. This could be explained by the vitrectomy procedure with 


\section{\begin{tabular}{ll|l} 
Macula thickness: macular cube $512 \times 128$ & OD $\bigcirc$ & $\bigcirc$
\end{tabular}}
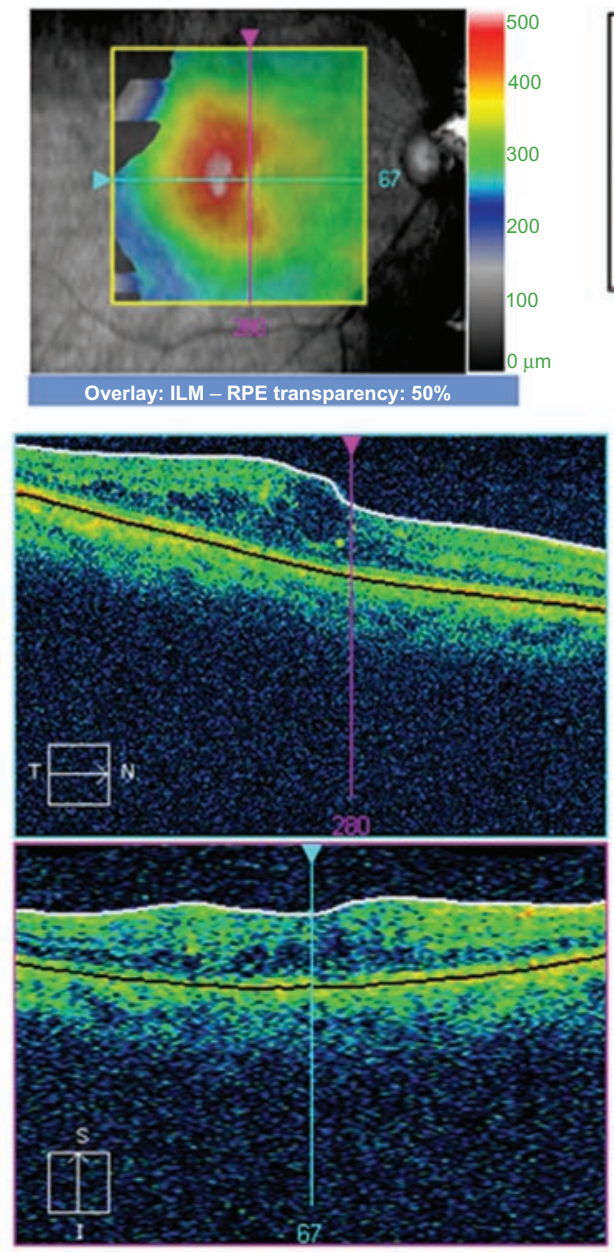
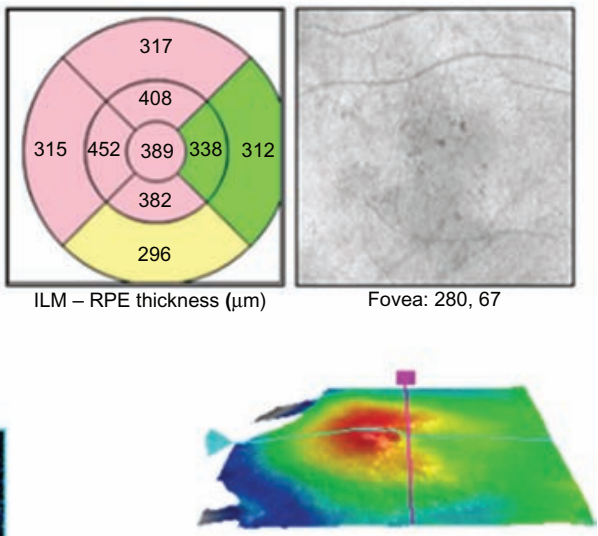

ILM - RPE

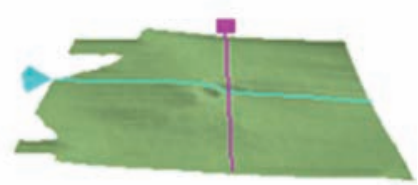

ILM

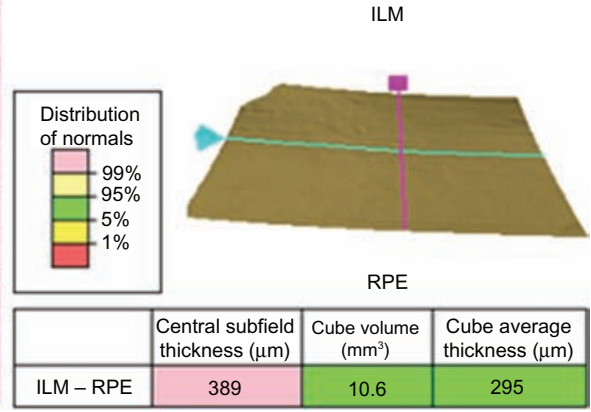

Figure 8 Optical coherence tomograph for the same patient in group 2 at the 12-month visit.

Abbreviations: ILM, inner limiting membrane; RPE, retinal pigment epithelium.

posterior hyaloid detachment that might result in relatively more damage to the foveal photoreceptors than with macular grid laser application.

Another important issue is the timing of intervention in relation to the severity of diabetic macular edema; in other words, grid laser was applied 2 weeks following the combined injection when the beneficial pharmacologic effects of the drugs had occurred and the diabetic macular edema had subsided. However, in group 1, vitrectomy with detachment of the posterior hyaloid was performed while the diabetic macular edema was maximum, resulting in more potential risk of damage.

When comparing the main outcome measurements in this trial, mean BCVA and central foveal thickness improvement were better in group 1 (ie, the vitrectomy group) at 3 months, with no further improvement seen at subsequent study visits. This could be explained by the nature of the procedure used, in that laser takes time to exert its effect on the retinal pigment epithelium and vitrectomy has an immediate effect on elimination of the inflammatory and growth factors as well as the potential mechanical effect of the posterior hyaloid and improvement in retinal oxygenation. Another explanation could be the enhanced pharmacologic effect of

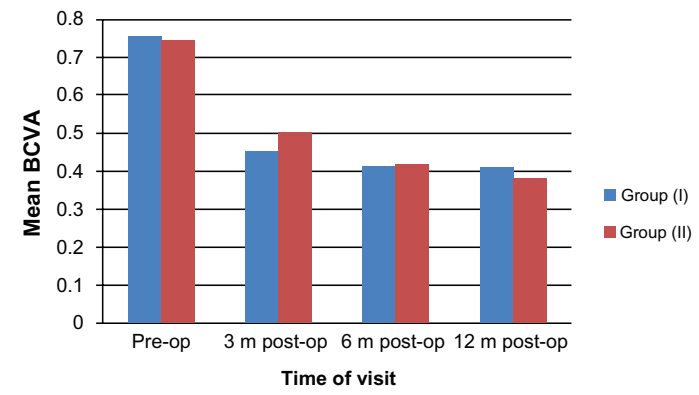

Figure 9 Mean BCVA measured by EDRTS chart during the study period. Abbreviations: BCVA, best-corrected visual acuity; EDTRS, Early Treatment Diabetic Retinopathy Study. 
Table 2 Mean BCVA and central foveal thickness compared between both groups during the study period

\begin{tabular}{|c|c|c|c|c|c|}
\hline Variable & Group & Mean & SD & $\begin{array}{l}\text { Student's } \\
\text { t-test }\end{array}$ & $P$ value \\
\hline \multirow[t]{2}{*}{ Preoperative BCVA } & Group I & 0.75 & 0.12 & 0.26 & 0.795 \\
\hline & Group 2 & 0.74 & 0.12 & & \\
\hline \multirow[t]{2}{*}{ BCVA at $3 \mathrm{~m}$ postoperatively } & Group I & 0.45 & 0.18 & 0.93 & 0.361 \\
\hline & Group 2 & 0.50 & 0.10 & & \\
\hline \multirow[t]{2}{*}{ BCVA $6 \mathrm{~m}$ postoperatively } & Group I & 0.41 & 0.06 & 0.14 & 0.884 \\
\hline & Group 2 & 0.42 & 0.08 & & \\
\hline \multirow[t]{2}{*}{ BCVA 12 m postoperatively } & Group I & 0.41 & 0.09 & 0.98 & 0.334 \\
\hline & Group 2 & 0.38 & 0.06 & & \\
\hline \multirow{2}{*}{ Baseline CFT } & Group I & 517 & 64 & 0.526 & 0.603 \\
\hline & Group 2 & 530 & 79 & & \\
\hline \multirow[t]{2}{*}{ CFT $3 \mathrm{~m}$ postoperatively } & Group I & 244 & 16 & 1.38 & 0.178 \\
\hline & Group 2 & 256 & 28 & & \\
\hline \multirow[t]{2}{*}{ CFT $6 \mathrm{~m}$ postoperatively } & Group I & 225 & 18 & 0.073 & 0.942 \\
\hline & Group 2 & 224 & 21 & & \\
\hline \multirow[t]{2}{*}{ CFT 12 m postoperatively } & Group I & 212 & 20 & 0.144 & 0.886 \\
\hline & Group 2 & 211 & 17 & & \\
\hline
\end{tabular}

Notes: BCVA was measured by EDRTS acuity log score chart. CFT was measured by OCT.

Abbreviations: BCVA, best-corrected visual acuity; CFT, central foveal thickness; EDTRS, Early Treatment Diabetic Retinopathy Study; m, months; OCT, optical coherence tomography.

better solubility and diffusion of the drugs injected into the retinal tissues of vitrectomized eyes, realizing the potential benefits earlier.

It was also observed that the mean central foveal thickness in each group showed maximum improvement at 3 months, with a subsequent small gradual increase in central foveal thickness at 6 and 12 months; however, this was still markedly less than baseline values. This is because the effect of the injected drug combination lasts for a short duration and the requirement for multiple reinjections are the major drawback of the presently available drugs. Also, further deterioration is very likely if macular edema redevelops. ${ }^{36-38}$

There was no difference recorded in mean central foveal thickness between eyes that had been treated with macular argon laser before the study (10 eyes, $66 \%$ in each group) and eyes that had received previous IVTA injection when comparing the 12-month results with baseline

Table 3 BCVA improvement and CFT change from baseline in both groups during the study period

\begin{tabular}{llll}
\hline Variable & Group I & Group 2 & P value \\
\hline BCVA improvement at $3 \mathrm{~m}$ & $0.30 \pm 0.2$ & $0.24 \pm 0.09$ & 0.227 \\
BCVA improvement at $6 \mathrm{~m}$ & $0.34 \pm 0.14$ & $0.33 \pm 0.12$ & 0.738 \\
BCVA improvement at I2 m & $0.34 \pm 0.16$ & $0.36 \pm 0.1$ & 0.75 \\
CFT change at $3 \mathrm{~m}$ & $273 \pm 54$ & $275 \pm 8.6$ & 0.938 \\
CFT change at 6 m & $292 \pm 54.9$ & $306 \pm 74.8$ & 0.553 \\
CFT change at $12 \mathrm{~m}$ & $305 \pm 62.43$ & $319.7 \pm 74.3$ & 0.558 \\
\hline
\end{tabular}

Note: BCVA measured by EDRTS acuity log score chart.

Abbreviations: BCVA, best-corrected visual acuity; CFT, central foveal thickness; EDTRS, Early Treatment Diabetic Retinopathy Study; m, months. values in either group $(P>0.05)$. This result is supported by the work of Kumar et $\mathrm{al}^{39}$ who observed no significant improvement in functional results in patients with diffuse diabetic macular edema when comparing vitrectomy with removal of the internal limiting membrane and grid laser photocoagulation.

When comparing the main outcome measurements in this trial (BCVA and central foveal thickness), it was found that group 2 achieved better results than group 1 by the end of the study period, although this difference did not reach statistical significance. Although there has been a considerable number of studies indicating an important role of the posterior hyaloid in the pathogenesis of diabetic macular edema, ${ }^{9,16,26}$ we did not find any additional effect of posterior hyaloid detachment over macular grid laser in this study. One possible cause for this discrepancy

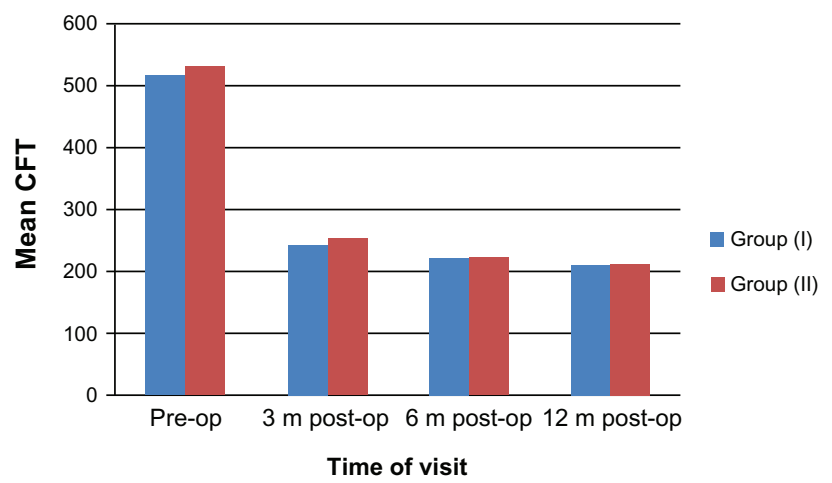

Figure 10 Mean CFT measured in microns during the study period. Abbreviation: CFT, central foveal thickness. 


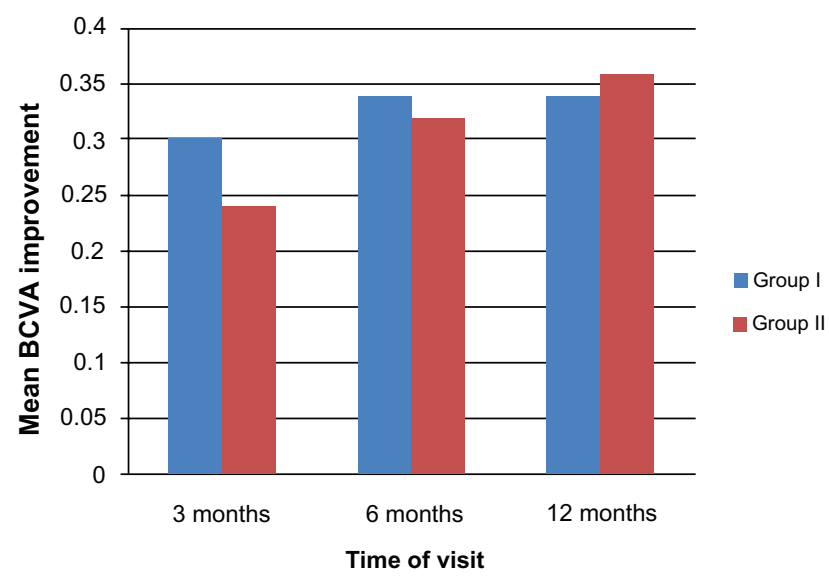

Figure I I Mean BCVA improvement from baseline in both groups during the study period.

Abbreviation: BCVA, best-corrected visual acuity.

is the chronic nature of diabetic macular edema and longstanding intraretinal diabetic changes with irreversible photoreceptor damage, and the selection of patients with type 2 diabetic mellitus, which may have had a negative impact on photoreceptor recovery in this elderly study population. The patients selected for this trial represent the typical situation in most elderly patients with type 2 diabetes where no clinically visible vitreomacular traction is present.

Other important points to account for the issue of why patients in group 2 showed a good response to the combined injection and subsequent grid laser although they had received combined IVTA injection and focal macular laser before are: first, the additive effect of bevacizumab and IVTA in reducing diffuse diabetic macular edema ${ }^{40-43}$ in terms of reduction in central foveal thickness (providing better results of subsequent laser application) and improvement in BCVA; second, grid

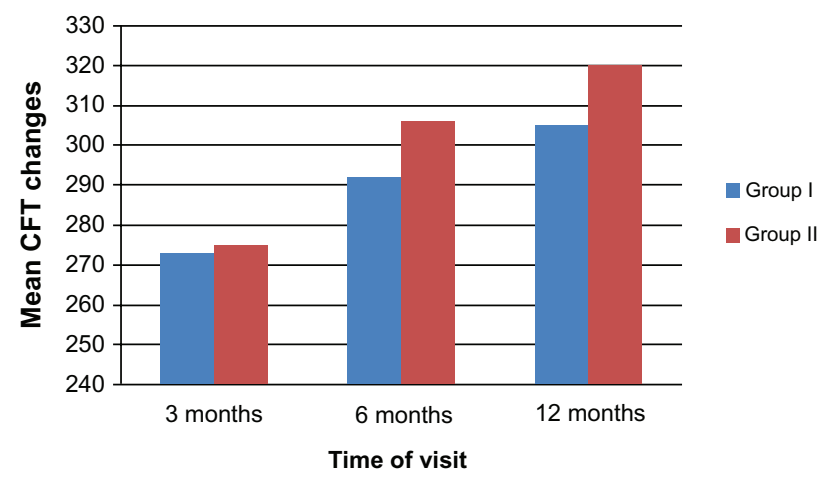

Figure 12 Mean change in CFT from baseline in both groups during the study period.

Abbreviation: CFT, central foveal thickness.
Table 4 Intraocular pressure values in both groups at baseline, I, 3 and 6 months post-intervention

\begin{tabular}{llllllll}
\hline Variable & \multicolumn{2}{l}{ Group I } & & \multicolumn{2}{l}{ Group 2 } & t-test & P value \\
\cline { 2 - 3 } & Mean & \pm SD & & Mean & \pm SD & & \\
\hline Baseline IOP & 14.27 & 2.76 & & 14.0 & 2.83 & 0.261 & 0.796 \\
IOP I m & 15.33 & 4.32 & & 19.27 & 6.32 & 1.99 & 0.056 \\
IOP 3 m & 14.27 & 1.71 & & 14.4 & 2.2 & 0.185 & 0.854 \\
IOP 6 m & 14.13 & 1.36 & & 14.47 & 2.29 & 0.484 & 0.632 \\
\hline
\end{tabular}

Abbreviations: IOP, intraocular pressure; SD, standard deviation.

laser applied (with the previously mentioned parameters) 2 weeks post-injection could have had a more beneficial effect ${ }^{44}$ than any other previous laser technique or timing; and third, only four eyes in group 2 had received combined IVTA injection and macular laser before inclusion in this trial, so the response of the group (15 eyes) was expected to be better when all patients received the triple approach.

The major adverse events were development of cataract (six cases in group 1 and three cases in group 2) and elevation of intraocular pressure (two cases in group 1 and seven cases in group 2). Cataract occurs as an unavoidable complication of pars plana vitrectomy (occurring in 66\% of phakic patients in group 1), is a common complication of IVTA $^{45}$ and bevacizumab injection (recorded in $33 \%$ of phakic patients in group 2), and also arises as a complication of diabetes itself. None of our cases showed a significant variation in BCVA or central foveal thickness, or a change in the nature of their macular edema following the successful phacoemulsification procedure. This may be an advantage of the perioperative topical nonsteroidal anti-inflammatory drops used and the absence of any surgical complications. ${ }^{46}$

Elevation of intraocular pressure was reported in two eyes (13.3\%) and seven eyes (46.6\%) in groups 1 and 2, respectively, which could be due to steroid responsiveness ${ }^{45,47}$ or decompensated trabecular dysfunction following the injection. More cases of elevated intraocular pressure were recorded in group 2 than in group 1, and this may be due to the easier washout of the IVTA in vitrectomized eyes. ${ }^{48}$

No other major complications, eg, endophthalmitis, retinal detachment, significant vitreous hemorrhage, choroidal hemorrhage, or atrophia bulbi, were recorded in this study, which of course enhanced the functional and anatomical results. The complication rate was comparable with that reported by other studies of macular surgery with posterior hyaloid detachment. 
The limitations of this study include its relatively small study population, that may have influenced the statistical results, and the lack of a control group. Further, the study design did not allow for assessment of the efficacy of the procedures in altering the natural course of diabetic macular edema, and also included a short observation time.

\section{Conclusion}

This study underlines the efficacy of both pars plana vitrectomy (with posterior hyaloid removal and without additional internal limiting membrane peeling) and macular grid laser, each combined with IVTA and bevacizumab injection, with regard to resorption of intractable diffuse diabetic macular edema (persistent or recurrent diabetic macular edema after laser photocoagulation or IVTA) even in eyes without vitreomacular traction. This combined therapy could represent a solution for the treatment of intractable diabetic macular edema, with a favorable long-term outcome. Both procedures seemed to improve BCVA and central foveal thickness, so this treatment option might be considered in the earlier stages of the disease to preserve vision. Combined treatment of IVTA and bevacizumab plus grid laser resulted in a more favorable functional and anatomic outcome because it provided a more durable improvement in BCVA and reduction in central foveal thickness at 12 months than vitrectomy combined with the same injections, and with relatively fewer complications. This small study favors the safer, cheaper, and more available line of treatment. Further studies of larger numbers of eyes and with a longer follow-up period are needed. The additive effect of triple therapy (pars plana vitrectomy, IVTA and bevacizumab injection, and postoperative grid laser) also needs to be evaluated.

\section{Disclosure}

The author reports no conflicts of interest in this work.

\section{References}

1. National Society to Prevent Blindness. Visual problems in the US Data Analysis Definition, Data Sources, Detailed Data Tables, Analysis, and Interpretation. New York, NY: National Society to Prevent Blindness; 1980 .

2. Williams R, Airey M, Baxter H. Epidemiology of diabetic retinopathy and macular edema: a systematic review. Eye. 2004;18:963-983.

3. Kubawara T, Cogan DG. Retinal vascular patterns VI: mural cells of the retinal capillaries. Arch Ophthalmol. 1962;69:492-502.

4. Williamson JR, Kilo C. Extracellular matrix changes in diabetes mellitus. In: Scarpelli DG, Migahi DG, editors. Comparative Pathobiology of Major Age-Related Diseases. New York, NY: Liss; 1984.

5. Ferris FL III, Patz A. Macular edema: a complication of diabetic retinopathy. Surv Ophthalmol. 1984;28:452-461.

6. Gandorfer A, Messmer EM, Ulbig MW, Kampik A. Resolution of diabetic macular edema after surgical removal of the posterior hyaloid and the inner limiting membrane. Retina. 2000;20:126-133.
7. Hikichi T, Fujio N, Akiba J, Azuma Y, Takahashi M, Yoshida A. Association between the short-term natural history of diabetic macular edema and the vitreomacular relationship in type II diabetes mellitus. Ophthalmology. 1997;104:473-478.

8. Ikeda T, Sato K, Katano T, Hayashi Y. Vitrectomy for cystoid macular oedema with attached posterior hyaloid membrane in patients with diabetes. Br J Ophthalmol. 1999;83:12-14.

9. Ikeda T, Sato K, Katano T, Hayashi Y. Improved visual acuity following pars plana vitrectomy for diabetic cystoid macular edema and detached posterior hyaloid. Retina. 2000;20:220-222.

10. Lewis H, Abrams GW, Blumenkranz MS, Campo RV. Vitrectomy for diabetic macular traction and edema associated with posterior hyaloidal traction. Ophthalmology. 1992;99:753-759.

11. Nasrallah FP, Jalkh AE, van Coppenolle F, et al The role of the vitreous in diabetic macular edema. Ophthalmology. 1998;95:1335-1339.

12. Pendergast SD, Hassan TS, Williams GA, et al. Vitrectomy for diffuse diabetic macular edema associated with a taut premacular posterior hyaloid. Am J Ophthalmol. 2000;130:178-186.

13. Stefánsson E. Physiology of vitreous surgery. Graefes Arch Clin Exp Ophthalmol. 2009;247:147-163.

14. Hartley KL, Smiddy WE, Flynn HW Jr, Murray TG. Pars plana vitrectomy with internal limiting membrane peeling for diabetic macular edema. Retina. 2008;28:410-419.

15. Harbour JW, Smiddy WE, Flynn HW, Rubsamen PE. Vitrectomy for diabetic macular edema associated with a thickened and taut posterior hyaloid membrane. Am J Ophthalmol. 1996;121:405-413.

16. Heij EC, Hendrikse F, Kessels AG, Derhaag PJ. Vitrectomy results in diabetic macular oedema without evident vitreomacular traction. Graefes Arch Clin Exp Ophthalmol. 2001;239:264-270.

17. Yanyali A, Horozoglu F, Celik E, Nohutcu AF. Long-term outcomes of pars plana vitrectomy with internal limiting membrane removal in diabetic macular edema. Retina. 2007;27:557-566.

18. Klein R, Klein B, Moss S. Visual impairment in diabetes. Ophthalmology. 1984;91:1-8.

19. The Early Treatment Diabetic Retinopathy Study Research Group. Photocoagulation for diabetic macular edema. Early Treatment Diabetic Retinopathy Study report No 1. Arch Ophthalmol. 1985;103:1796-1806.

20. Dillinger P, Mester U. Vitrectomy with removal of the internal limiting membrane in chronic diabetic macular oedema. Graefes Arch Clin Exp Ophthalmol. 2004;242:630-637.

21. Figueroa MS, Contreras I, Noval S. Surgical and anatomical outcomes of pars plana vitrectomy of diffuse nontractional diabetic macular edema. Retina. 2008;28:420-426.

22. Kuhn F, Kiss G, Mester V, et al. Vitrectomy with internal limiting membrane removal for clinically significant macular oedema. Graefes Arch Clin Exp Ophthalmol. 2004;242:402-408.

23. Rosenblatt BJ, Benson WE. Diabetic retinopathy. In: Yanoff M, Duker JS, editors. Ophthalmology, 2nd ed. St Louis, MO: Mosby; 2004.

24. Kent D, Vinores S, Campochiaro P. Macular edema: the role of soluble mediators. Br J Ophthalmol. 2000;84:542-545.

25. Kishi S, Shimizu K. Posterior vitreous precortical pocket. Arch Ophthalmol. 1990;108:979-982.

26. Tachi N, Ogino N. Vitrectomy for diffuse macular edema in cases of diabetic retinopathy. Am J Ophthalmol. 1996;122:258-260.

27. Stefánsson E, Novack RL, Hatchell DL. Vitrectomy prevents hypoxia in branch retinal vein occlusion. Invest Ophthalmol Vis Sci. 1990;31: 284-289.

28. Stefánsson E. Therapeutic effects of retinal laser treatment and vitrectomy. A theory based on oxygen and vascular physiology. Acta Ophthalmol Scand. 2001;79:435-440.

29. Recchia FM, Ruby AJ, Carvalho Recchia CA. Pars plana vitrectomy with removal of the internal limiting membrane in the treatment of persistent diabetic macular edema. Am J Ophthalmol. 2005;139:447-454.

30. Rosenblatt BJ, Shab GK, Sharma S, Bakal J. Pars plana vitrectomy with internal limiting membranectomy for refractory diabetic macular edema without a taut posterior hyaloid. Graefes Arch Clin Exp Ophthalmol. 2005;243:20-25. 
31. Stolba U, Binder S, Gruber D, Krebs I, Aggermann T, Neumaier B. Vitrectomy for persistent diffuse diabetic macular edema. Am J Ophthalmol. 2005;140:295-301.

32. Bahadir M, Ertan A, Mertoglu O. Visual acuity comparison of vitrectomy with and without internal limiting membrane removal in the treatment of diabetic macular edema. Int Ophthalmol. 2005;26:3-8.

33. Yamamoto T, Hitani K, Sato Y, et al. Pars plana vitrectomy with and without peeling of the inner limiting membrane for diabetic macular edema. Ophthalmologica. 2005;219:206-213.

34. Song JS, Sohn JH, Park KH. Evaluation of the efficacy of vitrectomy for persistent diabetic macular edema and associated factors predicting outcome. Korean J Ophthalmol. 2007;21:146-150.

35. Shah S, Patel M, Thomas D, et al. Factors predicting outcome of vitrectomy for diabetic macular oedema: results of a prospective study. Br J Ophthalmol. 2006;90:33-36.

36. Jonas JB, Spandau UH, Kamppeter BA, Vossmerbaeumer U, Harder B. Follow-up after intravitreal triamcinolone acetonide for diabetic macular edema. Eur J Ophthalmol. 2006;16:566-572.

37. Gillies MC, Sutter FK, Simpson JM, Larsson J, Ali H, Zhu M. Intravitreal triamcinolone for refractory diabetic macular edema: two-year results of a double-masked, placebo-controlled, randomized clinical trial. Ophthalmology. 2006;113:1533-1538.

38. Haritoglou C, Kook D, Neubauer A, et al. Intravitreal bevacizumab (Avastin) therapy for persistent diffuse diabetic macular edema. Retina. 2006;26:999-1005.

39. Kumar A, Sinha S, Azad R, Sharma YR, Vohra R. Comparative evaluation of vitrectomy and dye-enhanced ILM peel with grid laser in diffuse diabetic macular edema. Graefes Arch Clin Exp Ophthalmol. 2007;245:360-368.

40. Soheilian M, Ramezani A, Bijanzadeh B, et al. Intravitreal bevacizumab (Avastin) injection alone or combined with triamcinolone versus macular photocoagulation as primary treatment of diabetic macular edema. Retina. 2007;27:1187-1195.
41. Faghihi H, Roohipoor R, Mohammadi SF, et al. Intravitreal bevacizumab versus combined bevacizumab-triamcinolone versus macular laser photocoagulation in diabetic macular edema. Eur $J$ Ophthalmol. 2008;18:941-948.

42. Kumar V, Ghosh B, Raina UK, Goel N. Comparative therapy evaluation of intravitreal bevacizumab and triamcinolone acetonide on persistent diffuse diabetic macular edema. Am J Ophthalmol. 2008;146: 974-975.

43. Soheilian M, Garfami KH, Ramezani A, et al. Two-year results of a randomized trial of intravitreal bevacizumab alone or combined with triamcinolone versus laser in diabetic macular edema. Retina. 2012;32: 314-321.

44. Steijns D, Duijvesz D, Breedijk MA, van der Heijden GJ. Steroid injection in addition to macular laser grid photocoagulation in diabetic macular oedema: a systematic review. Acta Ophthalmol. 2010;88: 389-393.

45. Mohan R, Murlidharan AR. Steroid induced glaucoma and cataract. Indian J Ophthalmol. 1989;15:80-84.

46. Almeida DR, Johnson D, Hollands H, et al. Effect of prophylactic nonsteroidal antiinflammatory drugs on cystoid macular edema assessed using optical coherence tomography quantification of total macular volume after cataract surgery. J Cataract Refract Surg. 2008;34: 64-69.

47. Danis RP, Ciulla TA, Pratt LM, Anliker W. Intravitreal triamcinolone acetonide in exudative age-related macular degeneration. Retina. 2000;20:244-250.

48. Furino C, Micelli Ferrari T, Boscia F, Cardascla N, Recchimurzo N, Sborgia C. Triamcinolone-assisted pars plana vitrectomy for proliferative vitreoretinopathy. Retina. 2003;23:771-776.
Clinical Ophthalmology

\section{Publish your work in this journal}

Clinical Ophthalmology is an international, peer-reviewed journal covering all subspecialties within ophthalmology. Key topics include: Optometry; Visual science; Pharmacology and drug therapy in eye diseases; Basic Sciences; Primary and Secondary eye care; Patient Safety and Quality of Care Improvements. This journal is indexed on

Submit your manuscript here: http://www.dovepress.com/clinical-ophthalmology-journal

\section{Dovepress}

PubMed Central and CAS, and is the official journal of The Society of Clinical Ophthalmology (SCO). The manuscript management system is completely online and includes a very quick and fair peer-review system, which is all easy to use. Visit http://www.dovepress.com/ testimonials.php to read real quotes from published authors. 